Article

\title{
Phospholipase D (PLD) Response to Water Stress in Citrus Roots and Leaves
}

\author{
Fernando Alferez ${ }^{1, *}$, Jian $\mathrm{Wu}^{2}$ and James $\mathrm{H}$. Graham ${ }^{2}$ \\ 1 Department of Horticultural Sciences, Southwest Florida Research and Education Center (UF-IFAS), \\ Immokalee, FL 34142, USA \\ 2 Soil and Water Sciences Department, Citrus Research and Education Center (UF-IFAS), Lake Alfred, \\ FL 33850, USA; jianwu@ufl.edu (J.W.); jhgraham@ufl.edu (J.H.G.) \\ * Correspondence: alferez@ufl.edu; Tel.: +1-(239)-658-3426
}

Received: 15 November 2019; Accepted: 25 December 2019; Published: 27 December 2019

check for updates

\begin{abstract}
The effects of drought stress on phospholipase D (PLD) gene expression and enzymatic activity were investigated in 'Pineapple' sweet orange. PLDs are tissue-specific, with overlapping functions, and in response to stress they may interact with ABA signaling. Tissue specificity for expression of PLDs and their regulation are unknown in citrus. To assess PLD response to water stress and gene expression/regulation in citrus, we subjected potted seedlings to increasing levels of soil drought. Evapotranspirational demand (ET) was estimated by measuring weight loss in pots, and water stress was further assessed by measuring ABA content. Three treatments were performed over a 3-week period: (a) Control treatment without drought stress (100\% of daily ET); (b) mild water stress (50\% ET); and (c) severe water stress ( $0 \%$ ET). ABA content increased during drought stress in both roots and leaves, being higher in leaves than in roots by the end of the experiment for any stress condition assayed. PLD enzymatic activity was monitored and expression of five PLD genes was studied. PLD activity increased linearly over time in response to increased soil drought and was around three times higher in roots than in leaves. PLD activation occurred initially in roots and then in leaves. PLD gene expression in response to stress soil drought differed between roots and leaves. These results show the potential of PLD as a suitable indicator of stress severity in citrus.
\end{abstract}

Keywords: citrus; drought stress; hormonal response; root health

\section{Introduction}

Physiological responses of trees to the environment rely on factors such as leaf morphology and anatomy, along with xylem vessel area, size, and density, as they play a role in stomatal conductance, and subsequent biochemical changes that contribute to differences in functional capacities [1,2]. Among abiotic stresses affecting plant productivity, water stress is the most important environmental agent causing losses in crop yield and quality [3-6]. In citrus, water stress is a main cause of yield losses due to physiological alterations such as preharvest fruit drop and leaf abscission [7,8]. Also, water stress is an important determinant of final fruit quality since it may alter internal maturity attributes, including decrease in the ratio of total soluble solids to titratable acidity [9]. Deep understanding of the plant response to drought and subsequent water stress is needed to design strategies for coping with increasing water stress conditions in the near future due to climate change and demographic pressure in citrus growing regions.

The responses of plants to drought vary depending on the severity of the stress and the stage of drought progression. In this regard, it has been proposed that monitoring soil moisture status in combination with measuring molecular, biochemical, and physiological responses in the plant may allow quantification of plant responses to drought severity [10]. There are abundant evidences of 
signaling and communication between roots and the above ground portion of the plant in response to drought; the phytohormone abscisic acid (ABA) was first suggested by Loveys [11] to be a xylem-located signal produced under water stress that may cause a change in stomatal conductance. In general, biophysical response to water stress integrates with hormonal signaling and gene expression. In citrus, it has been shown that expression of some ABA signaling core components mirror the concentration of the hormone that accumulates during fruit maturation and in leaves in response to drought [12-14]. Recently, it has been shown that leaves from citrus plants are able to adjust their water status and are a relevant source of $\mathrm{ABA}$ for roots during water stress and that leaf dehydration is a requirement to trigger ABA-induced responses in roots [15]. The involvement of phospholipase D (PLD) in the response mediated by ABA to dehydration is well established in plants [16]. There is an interplay between ABA and phosphatidic acid (PA), a product from PLD hydrolyzation of membrane phospholipids. PA produced by PLD $\alpha$ in response to drought promotes ABA signaling [17]. Expression of PLD $\alpha$-encoding gene is induced by ABA and dehydration in different crop herbaceous plants such as wheat, cowpea and foxtail [18-20]. This interplay has been less studied in woody plants of horticultural interest. In citrus, previous work has shown the interplay between ABA synthesis and signaling with phospholipase gene expression and activity in individual organs such as fruit and leaves subjected to mild stress $[13,14]$. Hence, PLD activity may be a good indicator of water stress in citrus plants but the dynamics of its activation in response to different drought conditions and its relationship with ABA accumulation have not been studied in the whole citrus plant. Response to drought conditions can be different if water stress imposed is light, mild, or severe. Also, response to short term shock stress is different to response to progressive drying [21], a condition that is more common in woody crops such as citrus subjected to standard horticultural practices.

PLD is a heterogeneous family, consisting of six subfamilies in Arabidopsis, named $\alpha, \beta, \gamma, \delta$, $\varepsilon$, and $\zeta$ [22]. Different members of these subfamilies may act in response to different stresses or in modulating various developmental processes and may overlap and/or have cooperative functions during the response [22,23]. In particular, PLD $\alpha$, the predominant PLD form in plants [24], and PLD $\delta$ are involved in ABA signaling during transpirational water loss resulting in stomata control [25-28]. The role of other PLDs in response to drought and water stress is less well documented. In citrus, these subfamilies have also been identified, and their involvement in regulating response to mild water stress in fruit and leaves [13,14] indicates other subfamily members may be involved; however, the activation and regulation of different PLDs in the citrus tree in response to drought stress is completely unknown. In addition, to our knowledge there are no reports on the response of PLD in citrus to water deficiency in the soil. We hypothesize that PLD activity in the plant may be a good indicator of the soil water content, so it can help in making any decisions on grove irrigation.

With the aim of starting to unravel regulation of PLDs in the whole citrus plant in response to water deficit in the soil, we investigated the activation dynamics of different PLDs in roots and leaves during the response to gradual soil desiccation and its relationship with ABA in leaves and roots.

\section{Materials and Methods}

\subsection{Plant Material and Treatments}

Thirty nine-month-old 'Pineapple' sweet orange plants growing in 2.5-L containers of a general purpose peat-based soil (Pro-Mix BX; Premier Horticulture, Red Hill, PA, USA) were maintained in a greenhouse at the Citrus Research and Education Center (Lake Alfred, FL, USA, $28^{\circ} 5^{\prime} 37^{\prime \prime} \mathrm{N}$, $81^{\circ} 43^{\prime} 30^{\prime \prime} \mathrm{W}$; elevation $51 \mathrm{~m}$ asl). The average night/day temperature in the greenhouse was $34 / 20$ ${ }^{\circ} \mathrm{C}$, and the relative humidity varied between $45 \%$ and $100 \%$. Natural photoperiods were about 11 h. Evapotranspiration (ET) of plants was monitored prior to experimental treatments to determine the evapotranspiration rate of each. ET was calculated gravimetrically by measuring the weight lost daily from each pot. Then, ET was used to establish three irrigation treatments: fully watered control (receiving $1.00 \mathrm{rET}), 0.50 \mathrm{rET}$, and $0 \mathrm{rET}(n=4)$. The experiment was performed for three weeks and 
repeated three times. The average total water use (TWU) per plant was calculated as the sum of the water applied over the course of the experiment after 3 weeks of treatment. Tissue from roots and leaves from three biological replicates was periodically collected, frozen in liquid nitrogen, and stored at $-80^{\circ} \mathrm{C}$ until analysis.

\subsection{Extraction of PLD and Analysis of Enzymatic Activity}

One hundred milligrams of leaf or root tissues was immersed in liquid nitrogen and ground to a powder. The frozen powder was transferred to a centrifuge tube containing $2 \mathrm{~mL}$ of extraction buffer (1 mM EDTA, $100 \mathrm{mM}$ Tris-HCl (pH 7.5), 2\% PVPP, and sorbitol $0.15 \mathrm{M}$ ), and vortexed to homogenize. The homogenized extract was centrifuged at $8900 \times g$ for $15 \mathrm{~min}$. After centrifugation, the pellet was washed three times and resuspended again in assay buffer $\left(250 \mathrm{mM}\right.$ Tris- $\mathrm{HCl}$ and $25 \mathrm{mM} \mathrm{CaCl} 2, \mathrm{pH}^{2}$ 8.0) for PLD analysis [29]. The procedure was carried out at $4{ }^{\circ} \mathrm{C}$. PLD activity was assayed with the Amplex Red Phospholipase Assay Kit (Molecular Probes, Invitrogen, Eugene, OR, USA) following manufacturer's instructions and using a fluorescence microplate reader with absorption and emission of fluorescence maxima set at 571 and $585 \mathrm{~nm}$, respectively. Enzymatic activity was expressed as absorbance units per $g$ of fresh weight.

\subsection{RNA Extraction and Analysis of Gene Expression}

Total RNA was extracted and purified from $100 \mathrm{mg}$ of leaf or root tissues using the RNeasy Mini Kit (Qiagen, Valencia, CA, USA). Then, $0.5 \mu \mathrm{g}$ were treated with DNaseI (Promega Corporation, Madison, WI, USA) to remove genomic DNA contamination and reverse transcribed using 'SuperscriptIII' reverse transcriptase (Invitrogen, Eugene, OR, USA) according to manufacturer's instructions. The cDNA was diluted 1.5-fold and stored at $-20{ }^{\circ} \mathrm{C}$ until needed.

An Applied Biosystems 7500 Fast Real-Time PCR system (Applied Biosystems, Foster City, CA, USA) was utilized for quantitative real-time RT-PCR analysis. Analysis was performed on 1 $\mu \mathrm{L}$ of diluted cDNA in a final reaction volume of $20 \mu \mathrm{L}$ using the SYBR ${ }^{\circledR}$ Green PCR Master Mix (Qiagen, Valencia, CA, USA). PCR conditions were as follows: $50{ }^{\circ} \mathrm{C}$ for $2 \mathrm{~min}$; $95{ }^{\circ} \mathrm{C}$ for $10 \mathrm{~min}$ followed by 40 cycles of $95^{\circ} \mathrm{C}$ for $15 \mathrm{~s} ; 60^{\circ} \mathrm{C}$ for $1 \mathrm{~min}$. Melting curve analysis was performed to confirm target-specific amplification. Primer concentration was optimized, and primer validation was performed to enable relative gene expression analysis using the $2^{-\Delta \Delta C t}$ method [30]. Citrus glyceraldehyde-3-phosphate-dehydrogenase (CsGAPDH), whose constitutive expression during water stress was previously confirmed [12], was used as an endogenous control, and primers used for $C s P L D \alpha, C s P L D \beta, C s P L D \gamma, C s P L D \delta, C s P L D \delta$, and $C s P L D \zeta$ were previously designed, validated, and reported. Sequences for primer design were obtained from Phytozome database (www.phytozome.org) and used for primer design [12] (Table S1). At least three biological replicates from each time point were utilized. All analyses were repeated in duplicate and results averaged for each replicate. The lowest expression value was used to compare all others within one experiment.

\subsection{ABA Extraction and Analysis}

At the end of the experiment, ABA was extracted in triplicate from ground samples of $1 \mathrm{~g}$ of fresh weight leaves or roots with $80 \%$ acetone containing $0.5 \mathrm{~g} \mathrm{~L}^{-1}$ citric acid and $100 \mathrm{mg} \mathrm{L}^{-1}$ of butylated hydroxytoluene. The extracts were centrifuged at 3000 $\mathrm{g}$ and the supernatant diluted in an appropriate volume of ice-cold TBS (6.05 $\mathrm{g}$ Tris, $8.8 \mathrm{~g} \mathrm{~L}^{-1} \mathrm{NaCl}$, and $0.2 \mathrm{mg} \mathrm{L}^{-1} \mathrm{MgCl}_{2}$ at $\mathrm{pH}$ 7.8) [31]. Three samples for each dilution were analyzed by an indirect enzyme-linked immunosorbent assay (ELISA), using the monoclonal antibodies from Phytodetek1 (Agdia, Elkhart, IN, USA) following manufacturer's instructions. The ABA content was calculated by interpolation with the logit transformation of the ABA standard curve [32]. 


\subsection{Statistical Methods}

Results are the means of three replicate samples \pm standard error (SE). Statistical analyses were performed by one-way ANOVA using SAS (SAS Institute Inc., Cary, NC, USA) followed by a Student-Newman-Keuls test to assess significant differences $(p<0.05)$ between pairs of means for each time point.

\section{Results and Discussion}

In this study, we investigated the effect of increasing water stress on PLD activation in the whole citrus plant, with the objective of identifying drought conditions in the soil necessary for induction of this enzymatic activity in the tree that could serve as an indicator of deleterious water stress. Since PLD interplays with ABA in the response of plants to water stress [17-20], the aim of this study was to investigate how drought, ABA accumulation, and PLD activation operate in citrus trees.

\subsection{Effects of Water Stress on ABA Accumulation}

Plants were subjected to different conditions of drought stress for 3 weeks. Whole-plant ET was calculated by the end of every drying period to establish three irrigation treatments. ET is a good indicator of water stress $[33,34]$. Severe drought $(0 \% \mathrm{ET})$ was imposed to the plants to reduce the water usage at the end of each dehydration treatment, whereas water use followed a linear fashion during the experiment in 100\% ET and 50\% ET plants (Figure 1A). ABA content increased during drought stress in both roots and leaves. By the end of the experiment, ABA content was higher in leaves than in roots for any stress condition assayed. Interestingly, these differences were more pronounced as plants were less stressed: 2-fold for 100\% ET, 8-fold for 50\% ET, and around 10-fold for 100\% ET plants (Figure 1B). Aboveground organs can be more sensitive than roots to soil drying [35], and this would explain higher ABA concentration in leaves than in roots. On the other hand, increase in ABA has been reported to be higher in shoots as compared to roots due to translocation in other crops such as apple in response to progressive drought [2]. Alternatively, more active carotenoid biosynthesis in leaves than in roots and reduction in carotenogenesis after water stress in roots [36] may also explain these differences. In this regard, citrus roots are unable to synthesize ABA de novo in response to dehydration, so ABA accumulation in roots relies on transport from shoots [37], and the role of leaves in sensing water deprivation seems crucial for ABA accumulation [15].

\subsection{Effects of Water Stress on PLD Activity}

In plants, PLD activates in response to dehydration produced by water stress: Activity increases within minutes of the onset of dehydration in the resurrection plant Craterostigma plantagineum [16] and also is dependent on stress severity in Petunia [10]. In citrus, PLD activates at transcriptional level in both leaves and fruit in response to mild water stress [14]. PLD enzymatic activity increased rapidly in roots after stress was imposed, whereas this increase was delayed in leaves. Withholding irrigation induced in roots a 2.5- (50\% ET) and a 3-fold (100\% ET) increase in total enzymatic activity by 1 week, whereas absence of water stress resulted in no PLD activation. The same but muted trend was observed in leaves. In both tissues, maximum activity was achieved by 2 weeks of water deprivation and decreased thereafter, although significant activation $(p<0.05)$ occurred earlier in roots (Figure 2$)$.

In both tissues there was a similar strong correlation $\left(r^{2}\right.$ values of 0.89 and 0.95 in leaves and roots, respectively) between severity of dehydration stress and PLD activity (Figure 3). Clearly, response mediated by PLD in the citrus tree depended on drought stress severity. Hence, severity and concomitant PLD activity can be manipulated by controlling soil water content as previously indicated [10]. Our results suggest that PLD activity in the plant is suitable as a very accurate indicator of water deficiency in the soil, so PLD activity can be used as a predictor of water needs in citrus. Since PLD activity increases in roots before leaves and ABA accumulates in leaves before roots and 
that ABA synthesis in roots appears to be less efficient than in leaves [36,37], our data suggest an ABA-independent mechanism for early accumulation of PLD in roots.

A
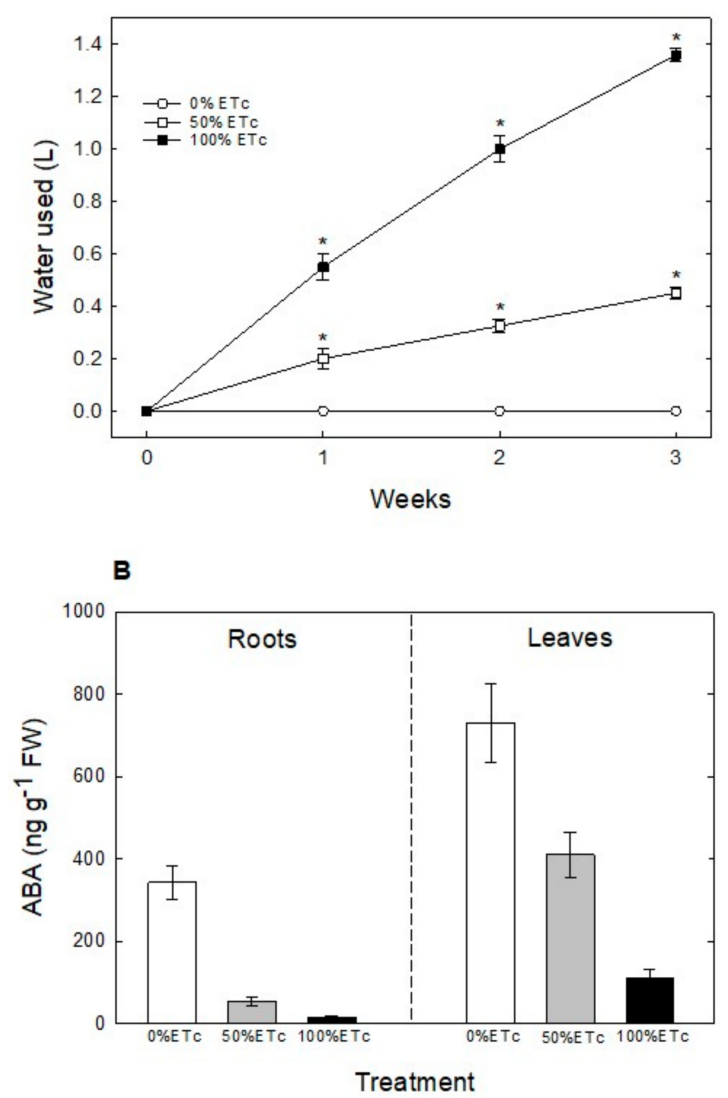

Figure 1. Water usage dynamics in response to three different water stress conditions: severe drought $(0 \%$ evapotranspiration (ET)), mild drought (\%50 ET), and fully watered plants (100\% ET). (A) Average accumulated water used (accumulated evapotranspiration requirement, in liters) in each treatment during a 3-week period. Asterisks indicate significant differences at ${ }^{*} p<0.05$. (B) ABA concentration in roots and leaves of 'Pineapple' sweet orange trees at the end of the 3-week experiment in the different irrigation regimes assayed.

\subsection{PLD Relative Gene Expression}

Several PLD-encoding genes from citrus have been identified in previous work [14], and the differential involvement of some PLD family members in the response of other plants to stress has been described [24]. In this work, we have studied the expression of five PLD-encoding genes ( $C S P L D \alpha, C s P L D \beta, C s P L D \gamma, C S P L D \delta$, and $C S P L D \zeta)$ in response to water stress conditions in aboveand below-ground parts of the citrus plant. Our analysis shows that PLD-encoding genes responded to drought in the soil following different spatiotemporal patterns in roots and leaves and that the response was dependent on severity of water deprivation. 


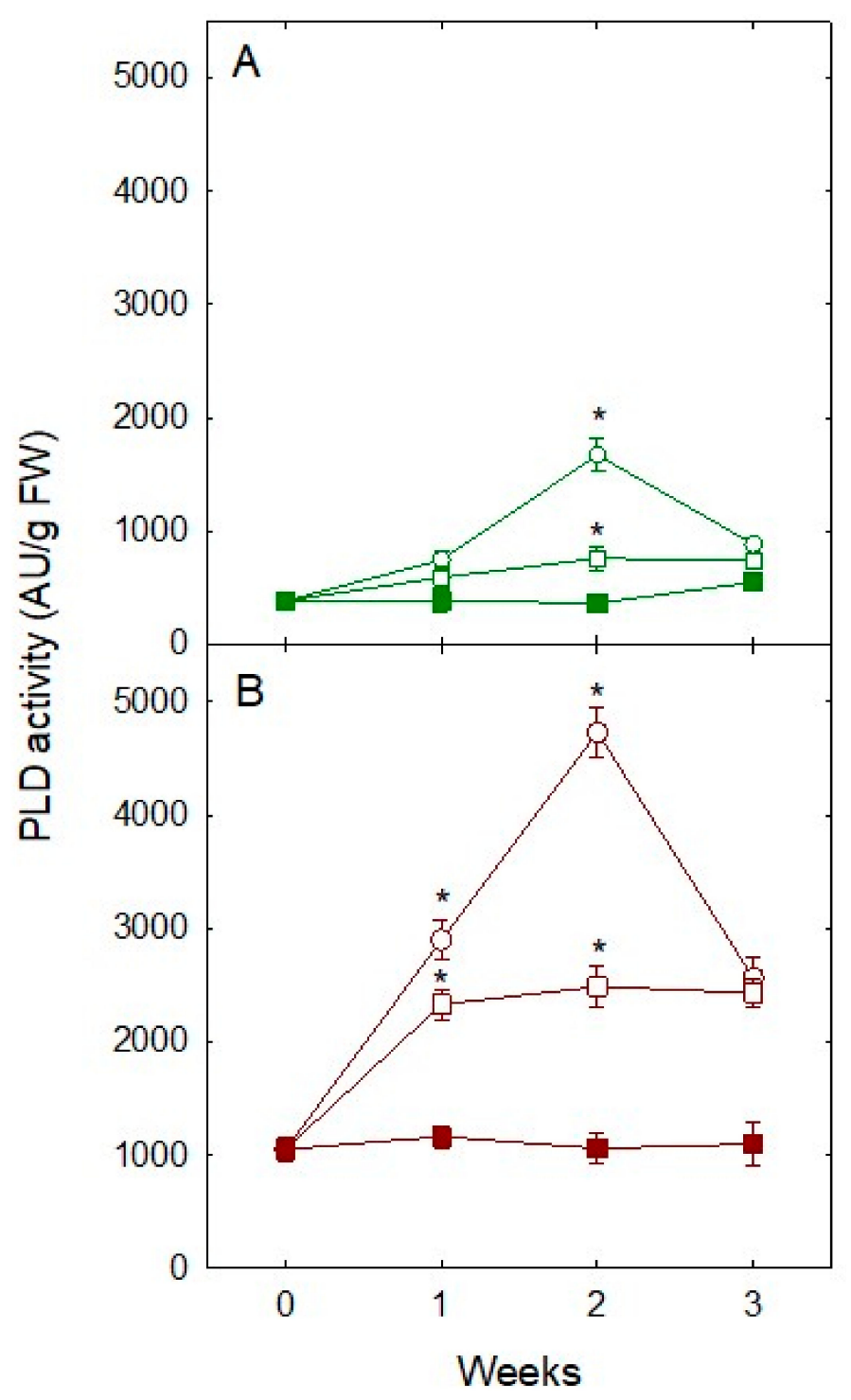

Figure 2. Phospholipase D (PLD) activity in response to different conditions of water stress (severe drought $(0 \% \mathrm{ET}, \mathrm{O})$, mild drought (\%50 ET, $\square)$, and fully watered plants $(100 \% \mathrm{ET}, \mathbf{\square}))$ in (A) leaves and (B) roots of 'Pineapple' sweet orange trees during a 3-week period. Data are means \pm SE of three biological replicates. Asterisks indicate significant differences at ${ }^{*} p<0.05$.

Interestingly, expression of genes encoding different PLDs did not change in roots or leaves of plants in well-watered soil $(100 \%$ ET). However, activation of these genes in response to the water deprivation imposed varied in both leaves and roots. Three different patterns of PLD gene expression in response to drought were observed. Pattern 1 was characterized by an earlier increase in expression in roots by 1 week and then in leaves, by 2 weeks CsPLD $\alpha, C s P L D \gamma$ and CsPLD $\delta$ followed this pattern (Figure 4). Expression of CsPLD $\alpha$ and $C s P L D \gamma$ was around 10 times higher in aerial parts than in roots. In contrast, expression of CsPLD $\delta$ was slightly higher in roots than in leaves of water stressed plants (20-fold as compared to 14-fold) (Figure 4). It has been suggested that PLD $\alpha$ and PLD $\delta$ cooperate in ABA signaling in stomata guard cells from leaves, but functions do not completely overlap [28]. In this regard, the higher induction of PLD $\alpha$ as compared to PLD $\delta$ supports previous findings [14] and strongly suggests different roles of both genes in response to soil drought. Notably, CSPLD $\gamma$ was upregulated in both leaves and roots in response to soil drought. This contrasts with previous findings [14] in citrus detached leaves, where this gene was downregulated under mild stress, and indicates different regulation in both systems. We cannot rule out an interplay between roots and 
leaves in the whole citrus plant system, because induction started earlier in roots than in leaves and this interplay would be lost in the detached-leaf system. A more detailed study on the physiological responses of the plant to the soil water deficit, involving determination of water status and dynamics in different tissues will be necessary to answer these questions. Interestingly, PLD 1 is highly induced in Arabidopsis roots after wounding but not in leaves [38]. This suggests that cellular damage occurs in roots after cycles of drought and rewatering in citrus.

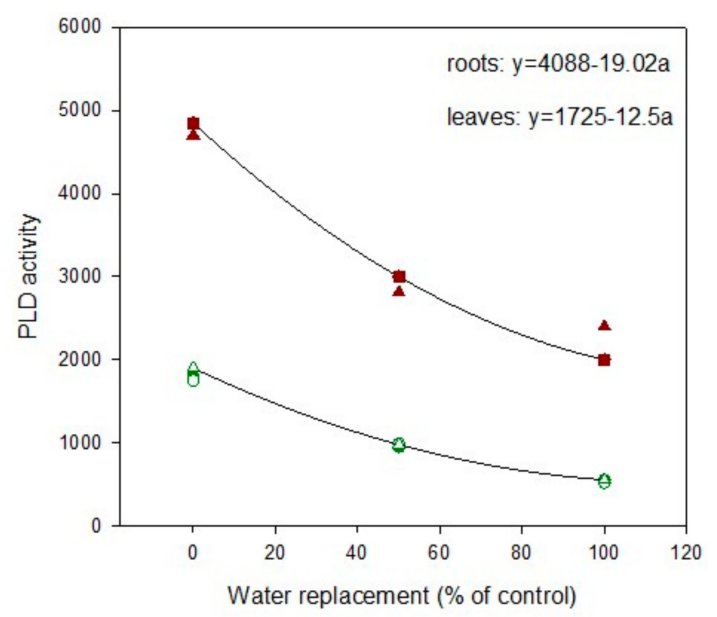

Figure 3. Correlation plots between percentage of water loss replacement and PLD activity at the end of the three-week experiment in roots (brown plot) and leaves (green plot). Three individual replicates were plotted for each water loss replacement value. The experiment was repeated three independent times with similar results.

\section{PATTERN 1}

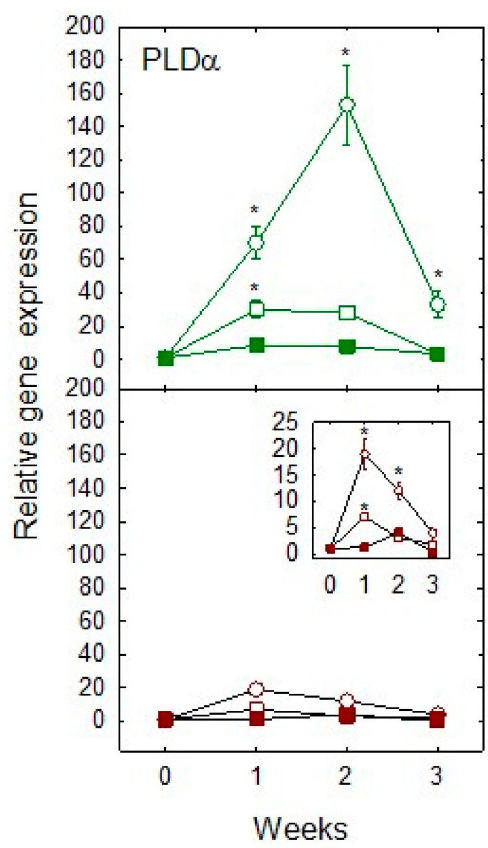

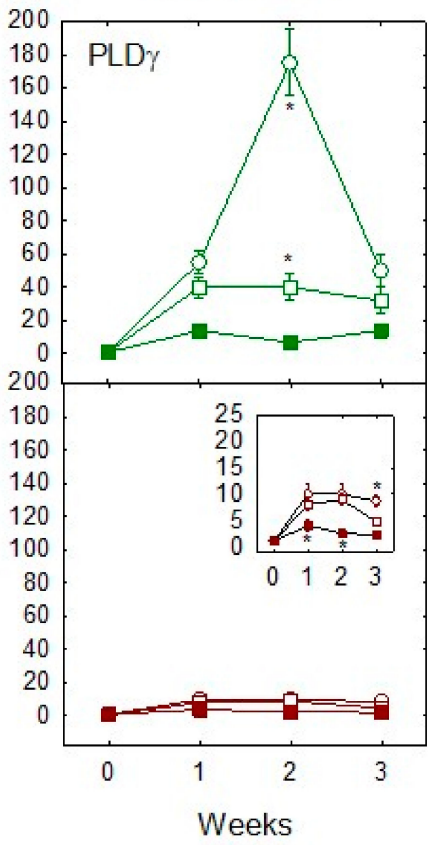

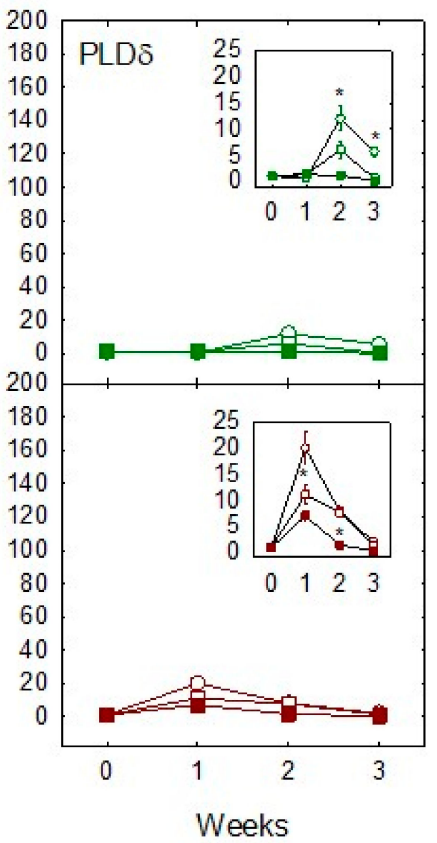

Figure 4. Effect on relative gene expression of different conditions of water stress (severe drought $(0 \%$ ET, O), mild drought ( $50 \% \mathrm{ET}, \square)$, and fully watered plants $(100 \% \mathrm{ET}, \mathbf{\square})$ ) in leaves (upper panels) and roots (lower panels) of 'Pineapple' sweet orange trees during a 3-week period. Pattern 1: Expression of $C s P L D \alpha, C s P L D \gamma$, and $C s P L D \delta$. Inset panels show magnified scale to appreciate differences. Data are means \pm SE of three biological replicates. Asterisks indicate significant differences at ${ }^{*} p<0.05$. 
CSPLD $\beta$ gene expression followed a different pattern in response to dehydration (pattern 2). Increase in expression in both roots and leaves started by 1 week of the imposed treatment. Whereas in roots gene expression steadily increased with time, in leaves expression was maximum by 2 weeks and decreased thereafter (Figure 5), showing an expression pattern coincident with that previously reported in detached leaves under mild water stress, although at much shorter times, and supporting that there is tissue-specificity in the induction of this isogene [14].

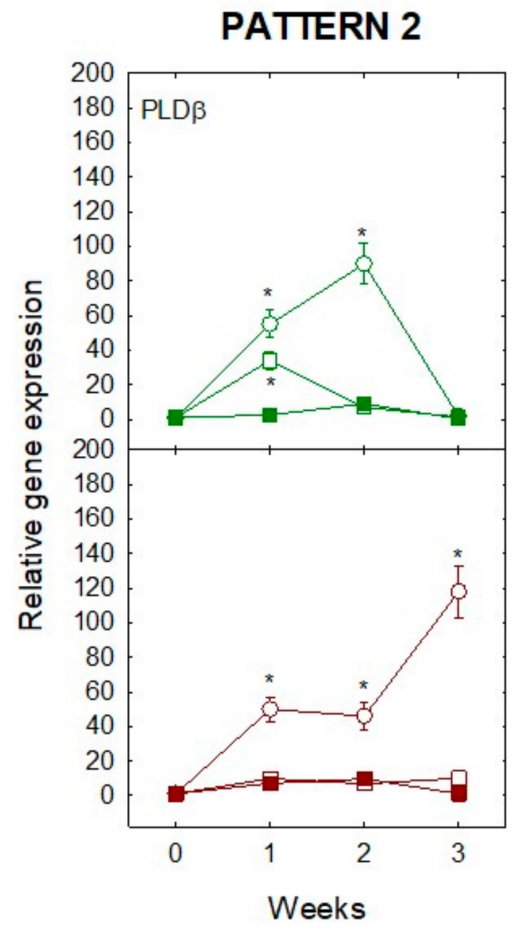

Figure 5. Effect on relative gene expression of different conditions of water stress (severe drought $(0 \%$ ET, O), mild drought (50\% ET, 口), and fully watered plants $(100 \% \mathrm{ET}, \mathbf{\square})$ ) in leaves (upper panel) and roots (lower panel) of 'Pineapple' sweet orange trees during a 3-week period. Pattern 2: Expression of $C S P L D \beta$. Data are means \pm SE of three biological replicates. Asterisks indicate significant differences at * $p<0.05$.

Expression of CSPLD $\zeta$ was not altered in leaves by any level of drought imposed, whereas in whole plants subjected to severe drought $(0 \% \mathrm{ET})$, a significant $\left({ }^{*} p<0.05\right) 5$-fold increase was measured in roots at the end of the experiment by 3 weeks (pattern 3, Figure 6), when root deterioration became apparent. This suggests that $P L D \zeta$ expression increases after prolonged stress and is a signal of tissue degradation. $P L D \zeta$ is involved in several responses to stress in plants. It increases in leaves and roots of Arabidopsis in response to phosphorus (P) starvation [39] and is involved in signaling of hypoxic stress [40]. To our knowledge, involvement in drought stress of this isogene has not been reported. The fact that increase in expression occurs only in roots and after prolonged stress indicates that this gene is involved in long-term responses to stress, but in citrus it is not activated in leaves. This reinforces the idea of overlapping complementary roles among different lipases. The differential expression of PLD subfamilies in response to nutrient availability has been reported in other plants [41], so this system may be of interest to study other stresses in citrus. 


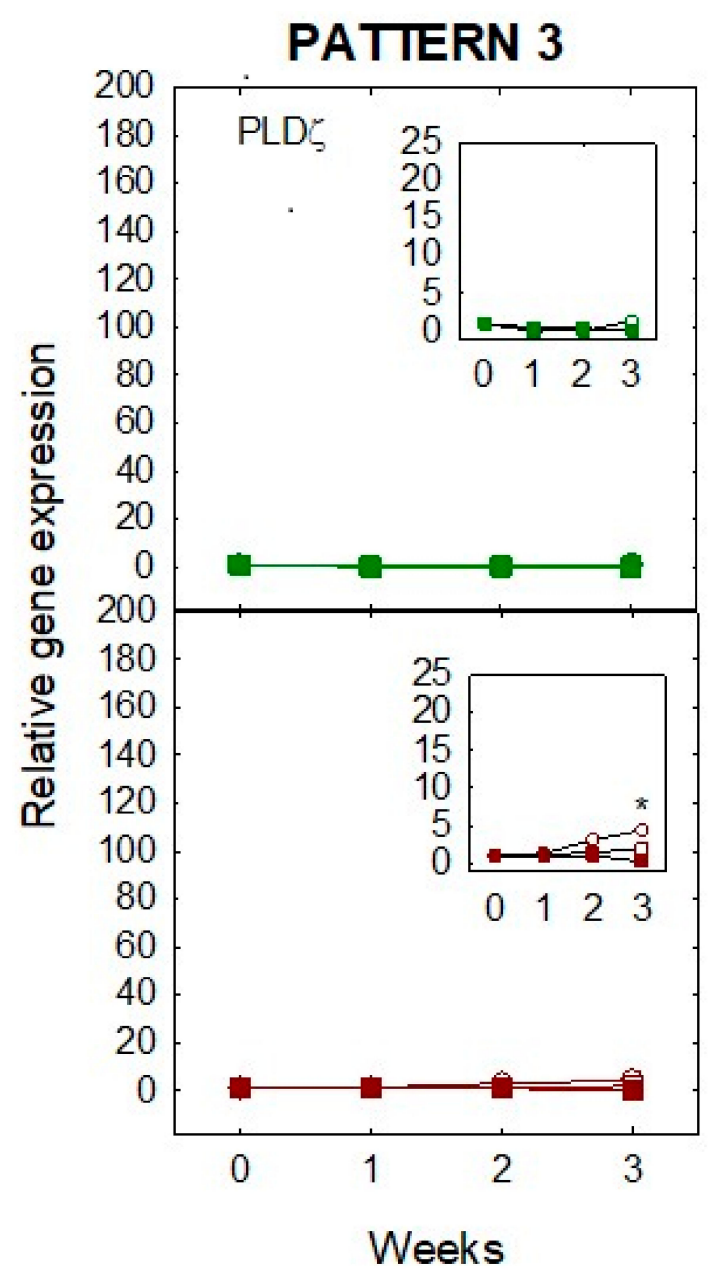

Figure 6. Effect on relative gene expression of different conditions of water stress (severe drought $(0 \%$ ET, O), mild drought (50\% ET, 口), and fully watered plants $(100 \% \mathrm{ET}, \mathbf{\square})$ ) in leaves (upper panel) and roots (lower panel) of 'Pineapple' sweet orange trees during a 3-week period. Pattern 3: Expression of $C s P L D \zeta$. Inset panels show magnified scale to appreciate differences. Data are means $\pm \mathrm{SE}$ of three biological replicates. Asterisks indicate significant differences at $p<0.05$.

\section{Conclusions}

In summary, we have shown that there is a differential activation of various PLD-encoding genes in response to increasing conditions of drought in the soil, linking directly soil water content with PLD gene expression. Furthermore, this activation is tissue specific. Resulting enzymatic activity shows a high correlation with severity of drought imposed, and hence, soil water content. Taken together, these results open the possibility of more precise evaluation of the water requirements of citrus trees. Our study shows also the potential of using different PLDs to study and understand response to other stresses in citrus. Since in our study PLDs gene expression was not activated in well-watered plants, this system shows promise in order to assess nutritional deficiencies and/or requirements in citrus.

Supplementary Materials: The following are available online at http://www.mdpi.com/2073-4395/10/1/45/s1, Table S1: Primers used for selected genes in qRT-PCR analysis.

Author Contributions: Conceptualization, F.A. and J.H.G.; Methodology, F.A.; Analysis, F.A. and J.W.; Writing, F.A. All authors contributed to the editing of this article. All authors have read and agreed to the published version of the manuscript.

Funding: This research received no external funding.

Conflicts of Interest: The authors declare no conflict of interest. 


\section{References}

1. Bhusal, N.; Bhusal, S.J.; Yoon, T.-M. Comparisons of physiological and anatomical characteristics between two cultivars in bi-leader apple trees (Malus $\times$ domestica Borkh.). Sci. Hortic. 2018, 231, 73-81. [CrossRef]

2. Bhusal, N.; Han, S.-G.; Yoon, T.-M. Impact of drought stress on photosynthetic response, leaf water potential, and stem sap flow in two cultivars in bi-leader apple trees (Malus $\times$ domestica Borkh.). Sci. Hortic. 2019, 246, 535-543. [CrossRef]

3. Boyer, J.S. Plant productivity and environment. Science 1982, 218, 443-448. [CrossRef] [PubMed]

4. Bray, E.A. Plant responses to water deficit. Trends Plant Sci. 1997, 2, 48-54. [CrossRef]

5. Deluc, L.; Quilici, D.; Decendit, A.; Grimplet, J.; Wheatley, M.; Schlauch, K.; Merillon, J.M.; Cushman, J.; Cramer, G. Water deficit alters differentially metabolic pathways affecting important flavor and quality traits in grape berries of Cabernet Sauvignon and Chardonnay. BMC Genom. 2009, 10, 212. [CrossRef]

6. Rizzini, F.M.; Bonghi, C.; Tonutti, P. Postharvest water loss induces marked changes in transcript profiling in skins of wine grape berries. Postharvest Biol. Technol. 2009, 52, 247-253. [CrossRef]

7. Gómez-Cadenas, A.; Tadeo, F.R.; Talon, M.; Primo-Millo, E. Leaf abscission induced by ethylene in water-stressed intact seedlings of Cleopatra mandarin requires previous abscisic acid accumulation in roots. Plant Phys. 1996, 112, 401-408. [CrossRef]

8. Iglesias, D.J.; Cercós, M.; Colmenero-Flores, J.M.; Naranjo, M.A.; Ríos, G.; Carrera, E.; Ruiz-Rivero, O.; Lliso, I.; Morillon, R.; Tadeo, F.R.; et al. Physiology of citrus fruiting. Braz. J. Plant Physiol. 2007, 19, $333-362$. [CrossRef]

9. Romero, P.; Navarro, J.M.; Pérez-Pérez, J.G.; García-Sánchez, F.; Gómez-Gómez, A.; Porras, I.; Martínez, V.; Botía, P. Deficit irrigation and rootstock: Their effects on water relations, vegetative development, yield, fruit quality and mineral nutrition of Clemenules mandarin. Tree Phys. 2006, 26, 1537-1548. [CrossRef]

10. Kim, J.; Malladi, A.; van Iersel, M.W. Physiological and molecular responses to drought in Petunia: The importance of stress severity. J. Exp. Bot. 2012, 63, 6335-6345. [CrossRef]

11. Loveys, B.R. Diurnal changes in water relations and abscisic acid in field-grown Vitis vinifera cultivars. III. The influence of xylem derived abscisic acid on leaf gas exchange. New Phytol. 1984, 98, 563-573. [CrossRef]

12. Romero, P.; Lafuente, M.T.; Rodrigo, M.J. The Citrus ABA signalosome: Identification and transcriptional regulation during sweet orange fruit ripening and leaf dehydration. J. Exp. Bot. 2012, 63, 4931-4945. [CrossRef] [PubMed]

13. Romero, P.; Gandia, M.; Alferez, F. Interplay between ABA and phospholipases A2 and D in the response of citrus fruit to postharvest dehydration. Plant Phys. Biochem. 2013, 70, 287-294. [CrossRef] [PubMed]

14. Romero, P.; Lafuente, M.T.; Alférez, F. A transcriptional approach to unravel the connection between phospholipases A2 and D and ABA signal in water stressed citrus fruit and leaves using a fruit specific ABA-deficient mutant. Plant Phys. Biochem. 2014, 80, 23-32. [CrossRef]

15. Manzi, M.; Pitarch-Bielsa, M.; Arbona, V.; Gomez-Cadenas, A. Leaf dehydration is needed to induce abscisic acid accumulation in roots of citrus plants. Environ. Exp. Bot. 2017, 139, 116-126. [CrossRef]

16. Frank, W.; Munnik, T.; Kerkmann, K.; Salamini, F.; Bartels, D. Water Deficit Triggers Phospholipase D Activity in the Resurrection Plant Craterostigma plantagineum. Plant Cell 2000, 12, 111-123. [CrossRef]

17. Zhang, W.; Qin, C.; Zhao, J.; Wang, X. Phospholipase D $\alpha 1$-derived phosphatidic acid interacts with ABI1 phosphatase 2C and regulates abscisic acid signaling. Proc. Natl. Acad. Sci. USA 2004, 101, 9508-9513. [CrossRef]

18. Wang, J.; Ding, B.; Guo, Y.; Li, M.; Chen, S.; Huang, G.; Xie, X. Overexpression of a wheat phospholipase D gene, $\mathrm{TaPLD} \alpha$, enhances tolerance to drought and osmotic stress in Arabidopsis thaliana. Planta 2014, 240, 103-115. [CrossRef]

19. El Maarouf, H.; Zuily-Fodil, Y.; Gareil, M.; d'Arcy-Lameta, A.; Pham-Thi, A.T. Enzymatic activity and gene expression under water stress of phospholipase D in two cultivars of Vigna unguiculata L. Walp. differing in drought tolerance. Plant Mol. Biol. 1999, 39, 1257-1265. [CrossRef]

20. Peng, Y.; Zhang, J.; Cao, G.; Xie, Y.; Liu, X.; Lu, M.; Wang, G. Overexpression of a PLD $\alpha 1$ gene from Setaria italica enhances the sensitivity of Arabidopsis to abscisic acid and improves its drought tolerance. Plant Cell Rep. 2010, 29, 793-802. [CrossRef]

21. Mane, S.P.; Vasquez-Robinet, C.; Sioson, A.W.; Heath, L.S.; Greene, R. Early PLD $\alpha$-mediated events in response to progressive drought stress in Arabidopsis: A transcriptome analysis. J. Exp. Bot. 2007, 58, $241-252$. [CrossRef] [PubMed] 
22. Wang, X. Regulatory functions of phospholipase D and phosphatidic acid in plant growth, development, and stress responses. Plant Phys. 2005, 139, 566-573. [CrossRef] [PubMed]

23. Wang, X.; Guo, L.; Wang, G.; Li, M. PLD: Phospholipase Ds in Plant Signaling. In Phospholipases in Plant Signaling; Wang, X., Ed.; Springer: Berlin/Heidelberg, Germany, 2014; pp. 3-26, ISBN 978-3-642-42011-5.

24. Hong, Y.; Zhang, W.; Wang, X. Phospholipase D and phosphatidic acid signalling in plant response to drought and salinity. Plant Cell Environ. 2010, 33, 627-635. [CrossRef] [PubMed]

25. Sang, Y.; Zheng, S.; Li, W.; Huang, B.; Wang, X. Regulation of plant water loss by manipulating the expression of phospholipase D $\alpha$. Plant J. 2001, 28, 135-144. [CrossRef]

26. Guo, L.; Devaiah, S.P.; Narasimhan, R.; Pan, X.; Zhang, Y.; Zhang, W.; Zhang, W.; Wang, X. Cytosolic glyceraldehyde-3-phosphate dehydrogenases interact with phospholipase D delta to transduce hydrogen peroxide signals in the Arabidopsis response to stress. Plant Cell 2012, 24, 2200-2212. [CrossRef]

27. Distefano, A.M.; Scuffi, D.; Garcia-Mata, C.; Lamattina, L.; Laxalt, A.M. Phospholipase Ddelta is involved in nitric oxide-induced stomatal closure. Planta 2012, 236, 1899-1907. [CrossRef]

28. Uraji, M.; Katagiri, T.; Okuma, E.; Ye, W.; Hossain, M.A.; Masuda, C.; Miura, A.; Nakamura, Y.; Mori, I.C.; Shinozaki, K.; et al. Cooperative function of PLD $\delta$ and PLD $\alpha 1$ in abscisic acid-induced stomatal closure in Arabidopsis. Plant Phys. 2012, 159, 450-460. [CrossRef]

29. Cronje, P.J.R.; Zacarias, L.; Alferez, F. Susceptibility to postharvest peel pitting in Citrus fruits as related to albedo thickness, water loss and phospholipase activity. Postharvest Biol. Technol. 2017, 123, 77-82. [CrossRef]

30. Livak, K.J.; Schmittgen, T.D. Analysis of relative gene expression data using 496 real-time quantitative PCR and the $2^{-\triangle \Delta C T}$ method. Methods 2001, 25, 402-408. [CrossRef]

31. Lafuente, M.T.; Martinez-Tellez, M.; Zacarias, L. Abscisic acid in the response of Fortune mandarins to chilling. Effect of maturity and high-temperature conditioning. J. Sci. Food Agric. 1997, 73, 494-502. [CrossRef]

32. Quarrie, S.A.; Whitford, P.N.; Appleford, N.E.J.; Wang, T.L.; Cook, S.K.; Henson, I.E.; Loveys, B.R. A monoclonal antibody to (S)-abscisic acid: Its characterization and use in a radioimmunoassay for measuring abscisic acid in crude extracts of cereal and lupin leaves. Planta 1988, 173, 330-339. [CrossRef] [PubMed]

33. Melgar, J.C.; Dunlop, J.M.; Syvertsen, J.P. Growth and physiological responses of the citrus rootstock Swingle citrumelo seedlings to partial rootzone drying and deficit irrigation. J. Agric. Sci. 2010, 148, 593-602. [CrossRef]

34. Romero-Conde, A.; Kusakabe, A.; Melgar, J.C. Physiological responses of citrus to partial rootzone drying irrigation. Sci. Hortic. 2014, 169, 234-238. [CrossRef]

35. Sharp, R.E.; Davies, W.J. Regulation of growth and development of plants growing with a restricted supply of water. In Plants under Stress; Jones, H.G., Flowers, T.L., Jones, M.B., Eds.; Cambridge University Press: Cambridge, UK, 1989; pp. 71-93, ISBN 0521344239.

36. Manzi, M.; Lado, J.; Rodrigo, M.J.; Zacarias, L.; Arbona, V.; Gómez-Cadenas, A. Root ABA accumulation in long-term water-stressed plants is sustained by hormone transport from aerial organs. Plant Cell Physiol. 2015, 56, 2457-2466. [CrossRef] [PubMed]

37. Manzi, M.; Lado, J.; Rodrigo, M.J.; Arbona, V.; Gómez-Cadenas, A. ABA accumulation in water-stressed Citrus roots does not rely on carotenoid content in this organ. Plant Sci. 2016, 252, 151-161. [CrossRef]

38. Qin, C.; Li, M.; Qin, W.; Bahn, S.C.; Wang, C.; Wang, X. Expression and characterization of Arabidopsis phospholipase D 2 2. Biochim. Biophys. Acta 2006, 1761, 1450-1458. [CrossRef]

39. Li, M.Y.; Welti, R.; Wang, X.M. Quantitative profiling of Arabidopsis polar glycerolipids in response to phosphorus starvation. Roles of phospholipases D zeta1 and D zeta2 in phosphatidylcholine hydrolysis and digalactosyldiacylglycerol accumulation in phosphorus starved plants. Plant Physiol. 2006, 142, 750-761. [CrossRef]

40. Lindberg, S.; Premkumar, A.; Rasmussen, U.; Schulz, A.; Lager, I. Phospholipases AtPLD $\zeta 1$ and AtPLD 22 function differently in hypoxia. Physiol. Plant. 2018, 162, 98-108. [CrossRef]

41. Hong, H.; Lu, S. Phospholipases in Plant Response to Nitrogen and Phosphorus Availability. In Phospholipases in Plant Signaling; Wang, X., Ed.; Springer: Berlin/Heidelberg, Germany, 2014; pp. 159-180, ISBN 978-3-642-42011-5. 